CSISA Policy and Research Note I 14

\title{
Development of Balanced Nutrient Management Innovations in South Asia: Lessons from Bangladesh India, Nepal, and Sri Lanka
} Avinash Kishore, Muzna Alvi, Timothy J. Krupnik

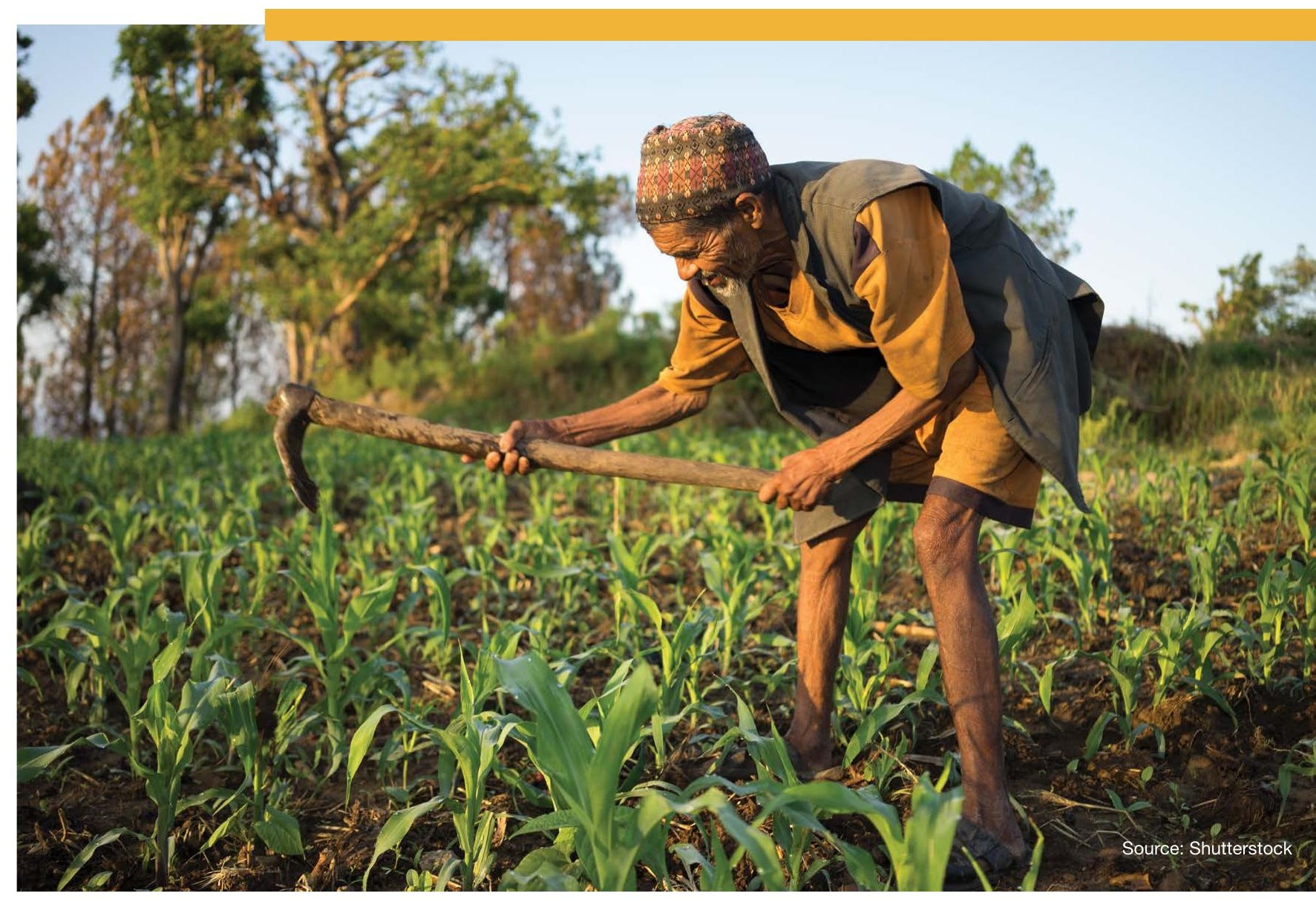




\section{Introduction}

As part of the United States Agency for International Development (USAID)/Washington and Bill and Melinda Gates Foundation supported Cereal Systems Initiative for South Asia (CSISA) and the USAID/Nepal Seeds and Fertilizer (NSAF) project, the International Food Policy Research Institute (IFPRI) and the International Maize and Wheat Improvement Center (CIMMYT) organized a Regional Dialogue on September 5, 2019, in Kathmandu on "Innovations for Advancing Farmers' Use of Balanced Nutrient Application in South Asia." The aim of the event was to facilitate cross-country dialogues on efficient nutrient management in the region. The event saw participation from central and regional government representatives from policy and extension, private fertilizer companies and fertilizer federations, researchers from CGIAR centers, as well as representatives of the donor community. Participants came from India, Nepal, Bangladesh, and Sri Lanka. Interactive discussions were centred around three main themes: (a) cross-country learning and evidence sharing on policies and subsidies to promote balanced nutrient application, (b) market, policy, and product innovations in the fertilizer industry, and (c) learnings and insights on the development of innovative methods in research and extension targeted to farmers. This policy brief summarizes seven key lessons learned from the discussions in the workshop.

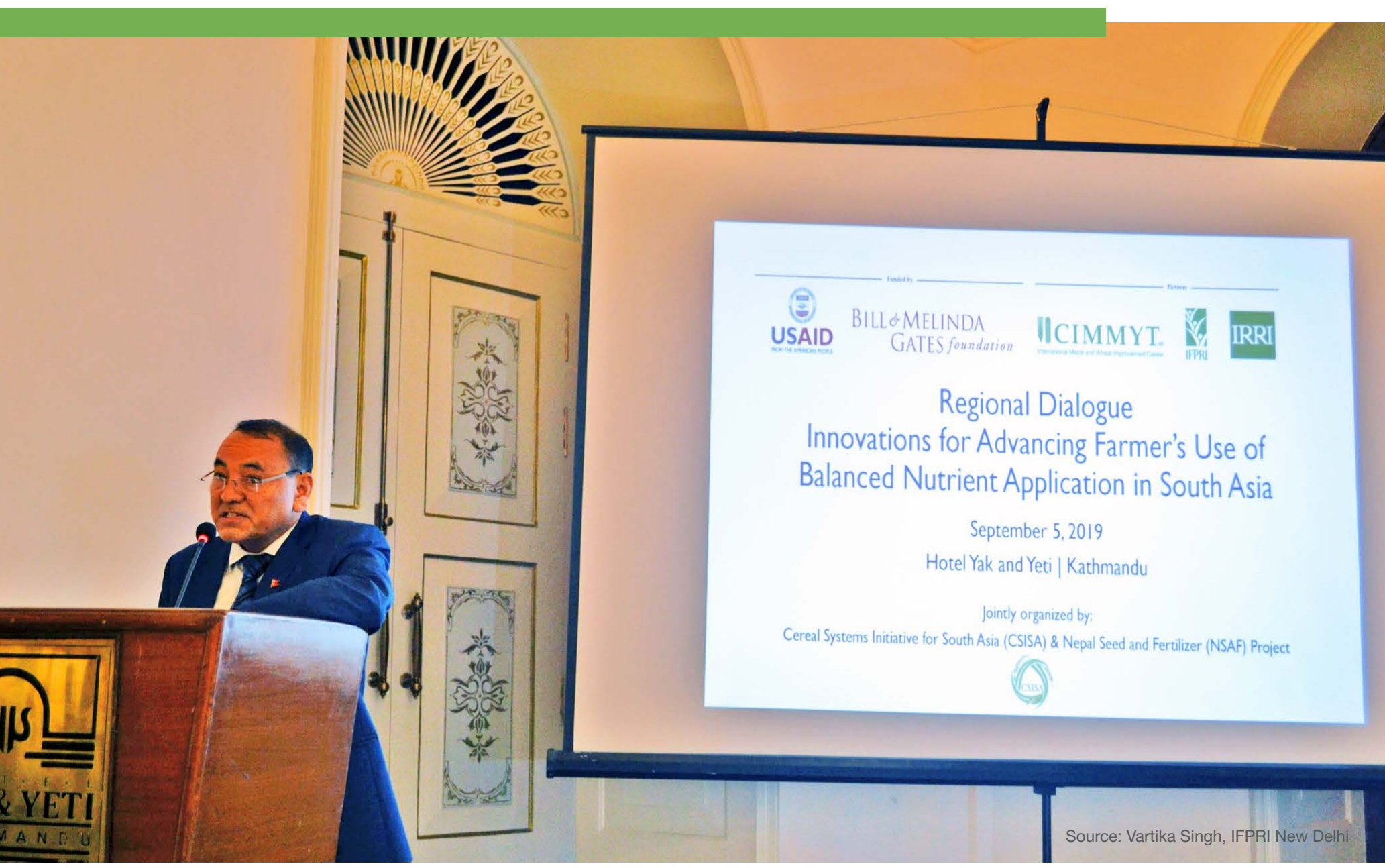

Dr. Yubak Dhoj GC, Secretary (Inputs) Ministry of Agriculture and Livestock Development, Nepal. 

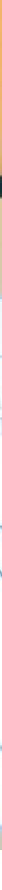

Mr. Navin Hada, Project Development Specialist, USAID, Nepal; Dr. Arabinda Kumar Padhee, Country Director, ICRISAT; Dr. Ramendra Singh, Head Agri (R\&D), Coromandel International, India. India's experience with DBT implementation - goals and challenges Mr. Ritesh Rautela, Senior Manager, MicroSave India; Md. Bashir Ahmed, Business Director, ACl Limited, Bangladesh

\section{Lesson 1: High macronutrient subsidies are common across South Asia}

All four countries - Bangladesh, India, Nepal, and Sri Lanka - heavily subsidize urea. Sri Lanka subsidizes urea, phosphate, and potassium-based fertilizers at 78 percent, 83 percent, and 80 percent of the global market price in the 2019 market (Figure 1). Subsidies on P and K are smaller in Bangladesh and Nepal. In India, subsidies on nitrogen-based fertilizers are also large and represent a substantial portion of the government's fiscal outlay. The current fertilizer subsidy regime in these countries appears to distort prices and farmers' incentives. A heavy subsidy on urea that ranges from 28 percent to 78 percent across countries, and little to no subsidy on micronutrients, appears to have led to an imbalanced application of fertilizers that can influence soil degradation in intensively cultivated areas of these countries.

Figure 1. Prices of urea, phosphate, and potash in Bangladesh, India, Nepal, and Sri Lanka in 2019 (in USD per kg)

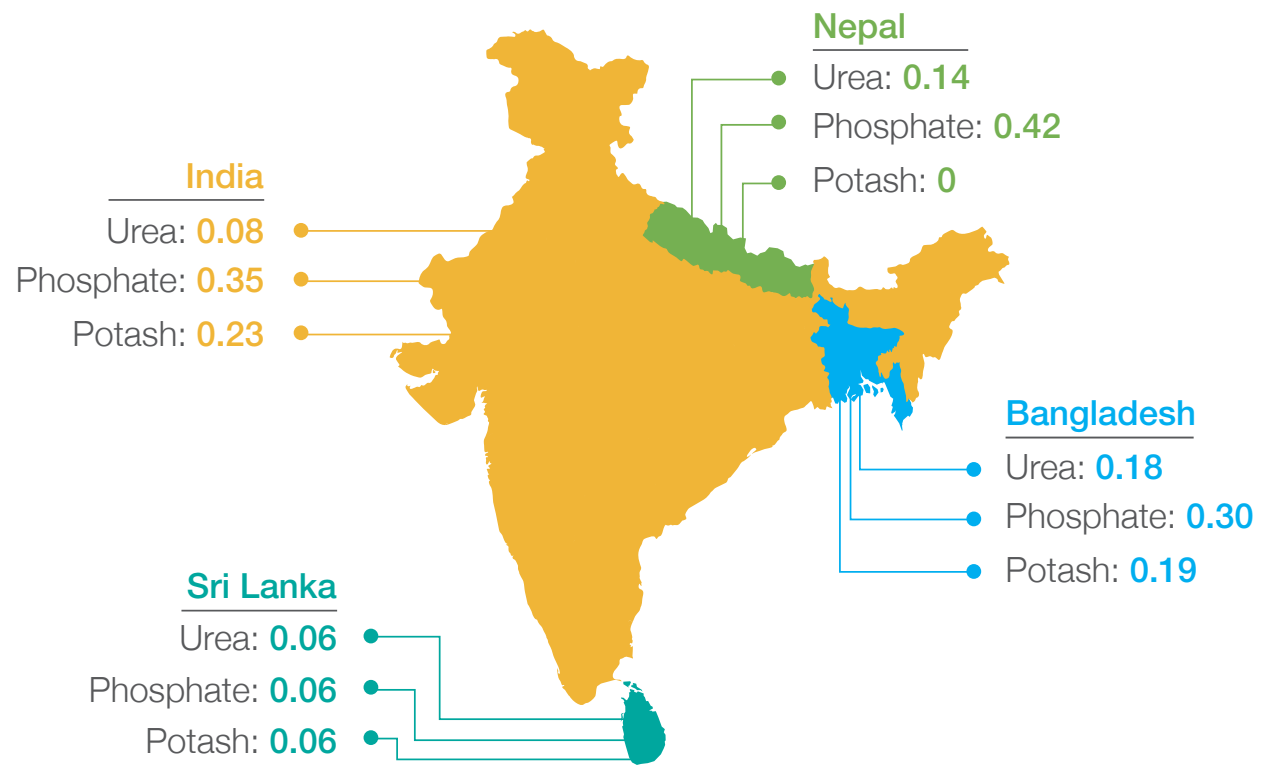

Source: Sri Lanka - http://ccfl.gov.Ik/web/index.php/en/products/fertilizer-price-list; Nepal, India, and Bangladesh Gazetted government sources. Note: Sri Lanka fertilizer rates are for paddy crop. The rate for other crops is US\$0.17/kg. Conversion rates used: Live mid-market rate from www.xe.com as of September 25, 2019. 


\section{Lesson 2: Abolition of fertilizer subsidies does not last}

There have been major changes in fertilizer subsidies across the region over the last 25 years. Bangladesh, Nepal, and Sri Lanka all experimented with abolishing or drastically reducing fertilizer subsidies, only to restore them after a few years. The impact of temporary abolition of these subsidies on farmers' welfare, farming practices, or balanced use of nutrients are not well documented. There has been little systematic analysis of the reasons for the abolition and subsequent reinstatement of fertilizer subsidies and their rates across the three countries. Understanding the reasons for these policy reversals could assist in devising more practical and economically sound policy recommendations. While abolishing subsidies may, in theory, be a desirable approach to correct for a long history of market distortions, it is unlikely to be politically feasible nor politically viable in South Asia.

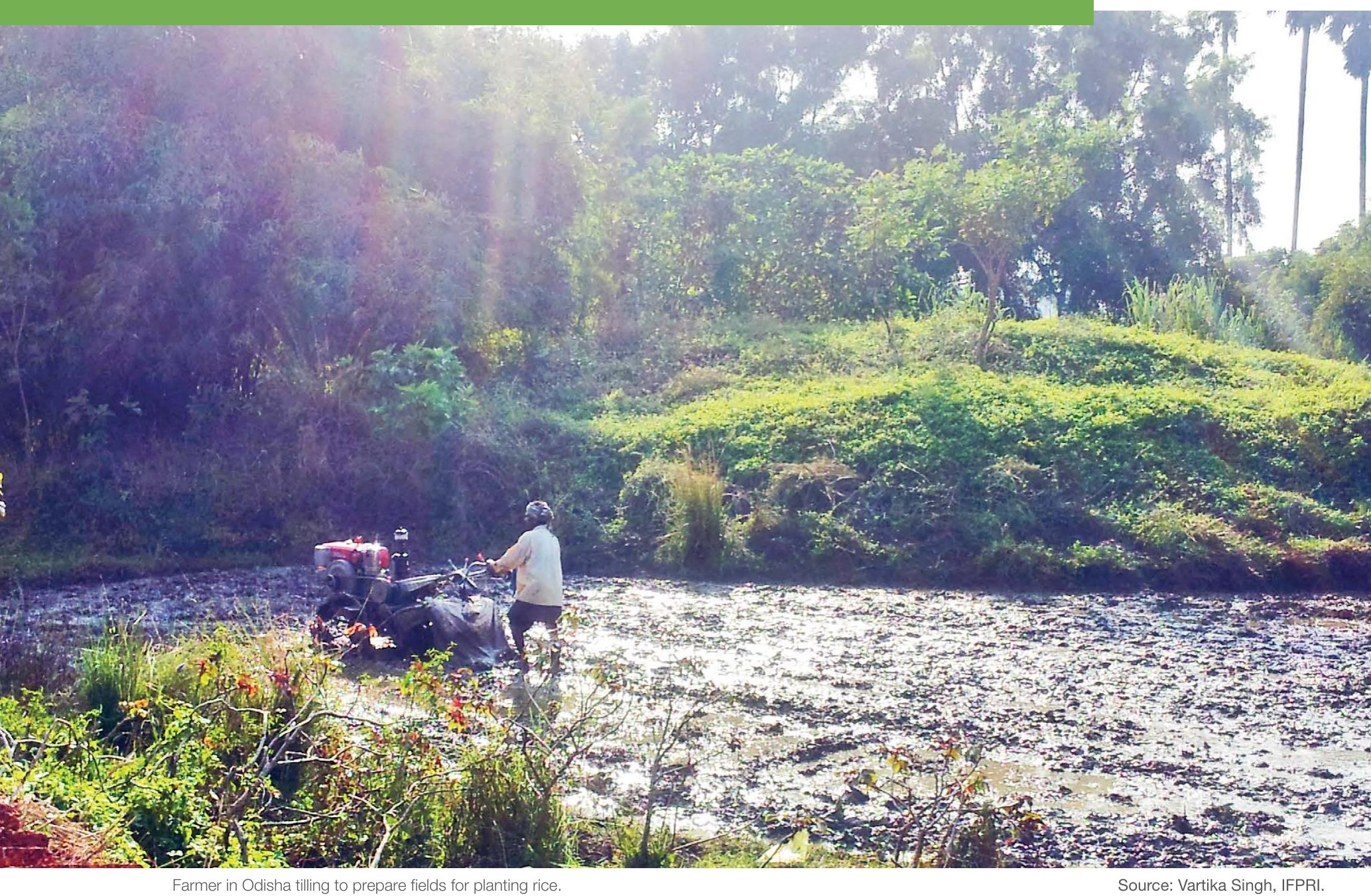




\section{Lesson 3: Farmers' response to sharp changes in fertilizer prices may be limited}

Unlike the other three countries, India never completely attempted to abolish fertilizer subsidies. However, the government of India decontrolled prices of phosphate and potash in 2011, resulting in a sharp increase in the retail prices of both nutrients. Following decontrol, the Government of India now fixes the total subsidy allocations for phosphate $(P)$ and potash $(K)$ fertilizers and permits retail prices to float with world prices. On the other hand, the retail price of urea continues to be controlled by the government.

CSISA's analysis of plot-level data on fertilizer use in India shows that the sharp increase in relative prices of $\mathrm{P}$ and $\mathrm{K}$ (Figure 1) resulted in only small changes in the application rates of the two nutrients to rice and wheat (Figure 2). Contrary to expectations, farmers' response to these changes in the relative prices of $\mathrm{N}$ (Urea), P (DAP), and K (MoP) fertilizers in India was surprisingly limited.

Figure 2. Limited observed responses to sharp changes in fertilizer prices in India: Prices of Urea, DAP, and MoP in India (June 2008-June 2013)

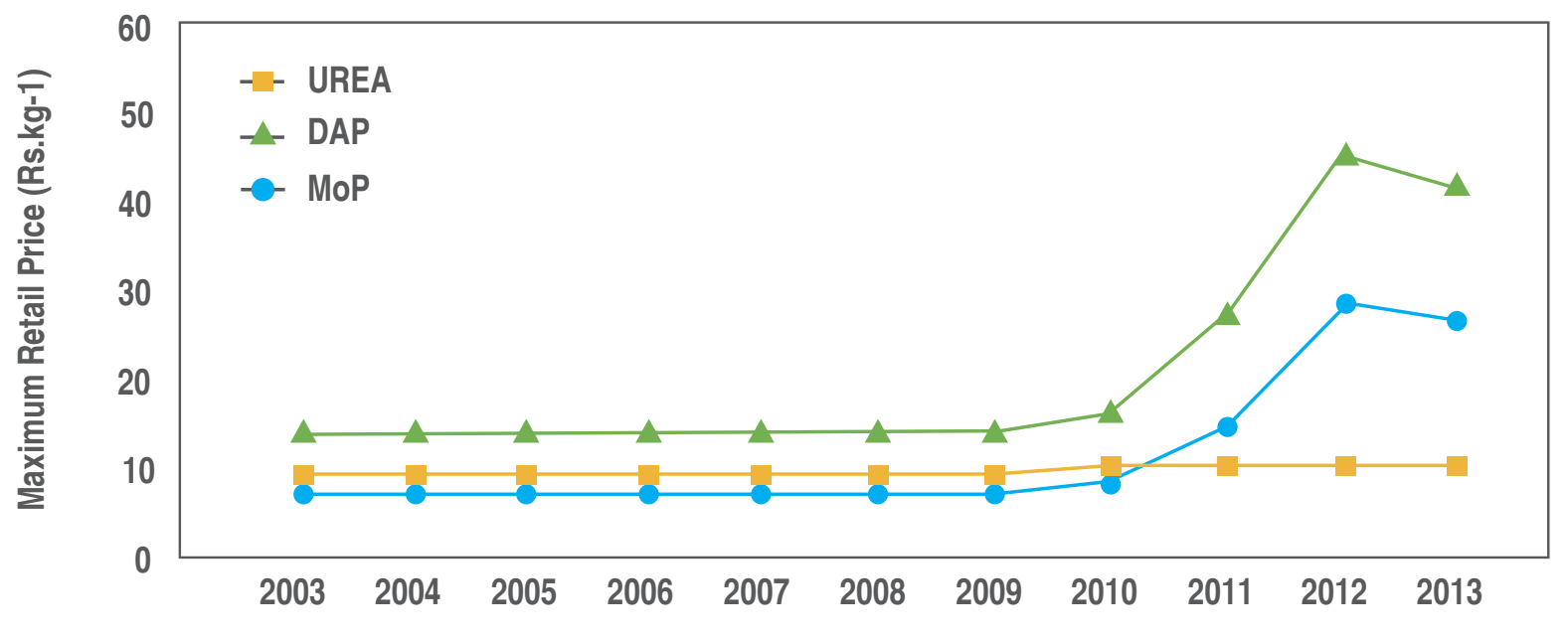

Source: Commission for Agricultural Costs and Prices (CACP), several rounds. Note: DAP = Phosphate; MoP = Potash; Rs = Indian Rupees

This lack of response to major changes in fertilizer subsidies suggests that rationalizing subsidies, though necessary, may not, by itself, lead to balanced application of fertilizers in India. This observation has important implications for other South Asian countries. Lack of information or understanding of crop nutrient requirements among policy planners and farmers is also a major problem. Besides correcting price incentives, there is a need for extension, backed by scientific research and recommendations, to nudge farmers to change behaviour regarding unbalanced and uneconomic fertilizer use. 
Figure 3. Average application rates (kg/ha) of N, P, and K in Kharif Paddy in India (2008-2013)

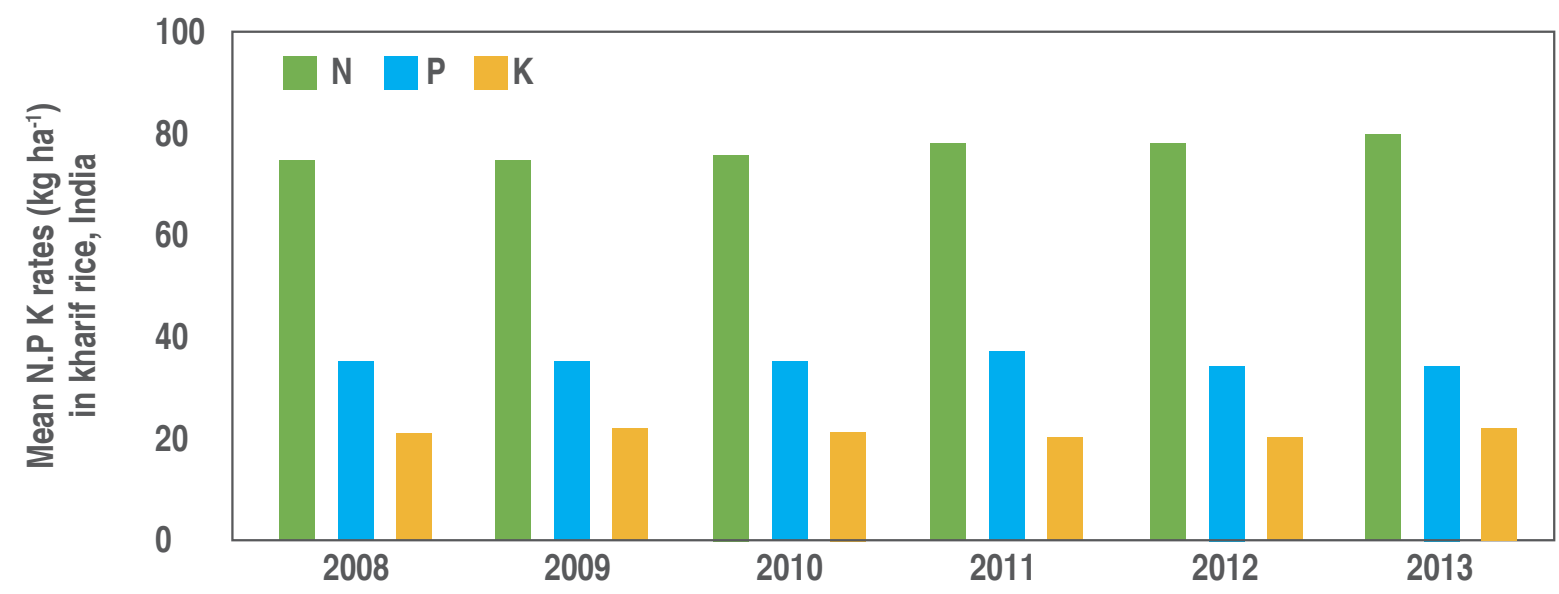

Source: Commission for Agricultural Costs and Prices (CACP), several rounds.

\section{Lesson 4: Providing soil health cards alone does not change farmers' management practices}

Extension that is effective in promoting balanced use of fertilizers was one of the key themes of the Kathmandu workshop. Both research institutions and fertilizer companies shared, compared, and contrasted their experiences in soil nutrient testing and extension recommendations. All four countries in the region have public programs to disseminate soil wet chemistry test-based fertilizer use recommendations. In 2015, the Government of India launched a large-scale program where 23.6 million soil samples were tested and 93 million soil health cards (SHCs) providing the results of these tests were distributed among farmers in the first phase. CSISA research in Bihar by IFPRI, however, has demonstrated just giving soil tests-based recommendations to farmers had a negligible effect on their understanding of crop nutrient requirements or actual fertilizer applications. Additional work by CIMMYT and the International Rice

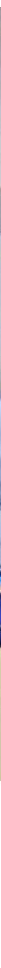


Research Institute (IRRI) in Bangladesh and India has found relatively poor relationships between soil nutrient tests and patterns of agricultural productivity for maize and rice, respectively. This appears to result from a mismatch between sampling time, frequency, and the specific tests conducted (for example, total nitrogen rather than available nitrogen, and so on). Extension research by Adventz, Precision Agriculture for Development (PAD) and IFPRI in other states such as Goa, Gujarat, and Odisha also show that few farmers (2-10 percent) who received SHCs understood test results and recommendations.

This does not mean that the SHC concept is a failed one. In independent projects, both IFPRI and PAD experimented with redesigning SHCs in Odisha and Gujarat. In both cases, simplifying the SHC and making it more user friendly led to significant improvement in the comprehension of soil health information. PAD and Adventz also found that repeated engagement with farmers through interactive call centers or personal visits by extension or fertilizer company staff can lead to increases in understanding of SHCs and a small, but significant, increase in the adoption of scientific soil fertility management recommendations. IRRI's experience of deploying app-based fertilizer recommendations to many farmers in different parts of India and Bangladesh also shows the need for a repeated engagement with farmers and field-level extension agents to increase understanding and generate impact. In other words, apps alone - no matter how advanced or comprehensive - are no substitute for educational efforts and dialogue with extension and farmers to advance improved nutrient management. Dr. Peter Crawford of CIMMYT also shared his experience of promoting balanced fertilizer use in Africa. He emphasized the need for farmers' needs assessments and human-centered design approaches while developing and delivering nutrient application recommendations and extension materials.

\section{Lesson 5: Fertilizer blends work, with caveats}

Fertilizer blends, both general and those customized for specific soils in specific locations, have emerged as a viable option to ensure complete plant nutrition and balanced soil nutrient application. There is now a considerable body of work dedicated to studying the best ways of producing and marketing custom blends that are based on agroecological and crop recommendations, in addition to digital soil mapping efforts led by CIMMYT in the region. Nepal also plans to set up its first fertilizer-blending plant, thus putting the issue of custom blends at centre-stage of the fertilizer policy debate in the region. With the proliferation of custom blends, the issue of how subsidies should be structured to promote the use of innovative products at an affordable price for smallholders also becomes important. While one solution is to subsidize end products, much like base fertilizers, there is a need for strong checks to ensure fertilizer blends are held to the same quality standards as other single-nutrient products.

The capital cost of setting up blending plants is very high, thus private fertilizer companies need strong research and development to assure the business case for investments, and to identify which technology to use for blending. Physical, or bulk, blending has been the most common process used until now. However, according to Dr Ramendra Singh of Coromandel International, this technology has also has disadvantages due to non-uniform release of nutrients from blended particles. Workshop participants discussed how this can lead to soil degradation and yield stagnation. Steam granulation and fusion blending are expensive but appear to be more efficient alternatives. A thorough cost-benefit analysis should guide decisions about which technology to adopt. 


\section{Lesson 6: Implementing direct cash transfer of fertilizer subsidies requires preparation}

The Government of Nepal is exploring the use of vouchers for fertilizer subsidies. The Government of India has also initiated a move to direct cash transfer (DCT) of fertilizer subsidies in a phased manner. Sri Lanka experimented with DCT for two years (four crop seasons) but reverted to the old system of price subsidies in early 2018. Both the ongoing attempts of the Government of India to implement DBT of fertilizer subsidies in phases and the short-lived DCT system in Sri Lanka have useful lessons for Nepal and other countries trying to introduce alternative forms of subsidy for fertilizers.

From 2005 to 2015, farmers in Sri Lanka enjoyed the highest subsidies on $\mathrm{N}, \mathrm{P}$, and $\mathrm{K}$ fertilizers in the region. All three nutrients were sold at US\$3 per $50 \mathrm{~kg}$ bag to paddy farmers. In February 2016, Sri Lanka however switched to direct cash transfer of a fertilizer subsidy. Retail prices of fertilizers increased 6.5-fold and farmers received a cash transfer directly to their bank accounts. Economists often prefer cash transfers to in-kind subsidies because the former does not distort prices. However, in Sri Lanka, the government continued to control fertilizer prices even after switching to DCT. During this period, prices of all three macronutrients remained equal, but at a level several times higher than before. Furthermore, while initially only paddy growers were eligible for the cash transfer, later, the government added a few more crops to the eligibility list. Farmers were entitled to a subsidy for up to only two hectares of cultivated land.

These restrictions and targeting requirements created a heavy burden of data collection and monitoring for agricultural extension and monitoring, resulting in irregularities and delays in subsidy delivery. Participants in the workshop learned that many stakeholders were dissatisfied with this system - a realization that has implications for the rest of the region. The government of Sri Lanka also returned to the old system of price subsidies soon after losing local body elections in 2018. Fertilizer prices in Sri Lanka are even lower now than they were before the introduction of cash transfers, with $\mathrm{N}, \mathrm{P}$, and $\mathrm{K}$ all sold at US\$2.75 for a $50 \mathrm{~kg}$ bag.
Fertilizer Vouchers: Lessons for Nepal

from the Neighbouring Countries

The Government of Nepal is considering using vouchers for fertilizers. The recent experience of implementing fertilizer subsidy reforms in India and Sri Lanka offers three lessons for Nepal, which hosted the policy dialogue:

Firstly, governments should not rush to a voucher system for fertilizer subsidies. A rushed reform may even backfire. Policymakers should first build a reliable database of farmers with their land records, to better target new subsidy regimes and assure that smallholders' benefit.

Secondly, if vouchers are to be targeted to a select group of farmers, initial targeting criteria should be as simple as possible. Complex targeting systems lead to higher probabilities of errors of omission and commission. Use of complicated indices for targeting leads to more discretion for lower bureaucrats and more errors and potential for misuse.

Thirdly, the use of fertilizer subsidies as an instrument to promote certain crops and discourage others has not been successful elsewhere in South Asia. Allowing fertilizer subsidies only for paddy in Sri Lanka made subsidy distribution more cumbersome (cropping pattern data had to be collected every season) and led to increased irregularities. Thus, a crop-neutral voucher policy should be explored. 
Unlike Sri Lanka, the Government of India plans to shift to cash transfers in a series of planned phases using new technologies to reduce transaction costs and irregularities. The government has installed point of sales (or POS) machines in all 0.22 million fertilizer retail outlets ${ }^{1}$. At present, farm input dealers have to validate all fertilizers sales to farmers using a biometric information unique identification document called Aadhar to control for leakages and fraud.

MicroSave, an Indian organization working closely with the government in monitoring the DBT system, shared results from its process evaluation of the implementation of Aadhar-linked fertilizer sales during the workshop. Poor internet connectivity has been a major challenge in the full implementation of Aadhar-linked sales of fertilizers. Aadhar cards are also not yet linked to land ownership records or soil health cards in most states. As a result, targeting of fertilizer subsidies and using cash transfers to promote recommended fertilizer rates and use remains a challenge.

Although theoretically promising, DBT of targeted subsidies therefore appears to be more challenging than universal subsidies. This is further complicated if operational landholding is used as the criterion for targeting because land records are not digitized and integrated with other farmer identity cards or citizen cards in most of South Asia.

\section{Lesson 7: Interest in organic fertilizers and improved organic matter management is growing}

There is rapidly growing interest in organic farming in all the countries in the region. With changing food and preferences and growing incomes, consumer demand is to some extent shifting towards organically grown produce, for fruits and vegetables. Several provincial governments in India have made budgetary provisions for promotion of organic farming in their respective states ${ }^{2}$. Independent organic farm entrepreneurs have also emerged in peri-urban areas bordering big cities, catering to an increasingly health conscious urban clientele. As demand for organic farm produce grows, governments will need to respond with appropriate fiscal and regulatory instruments to support the industry. This is also an opportunity for fostering cross-country learning on farming practices that could enhance productivity and ensure prices for organic produce remain competitive and accessible $^{3}$.

With the exception of Sri Lanka, workshop presenters and participants from India, Nepal, and Bangladesh - and especially those from the private sector - discussed their interest in growing organic fertilizer and compost markets. Although these products are likely to be best targeted to high-value horticultural and/or orchard crops as opposed to cereals in South Asia, organic amendments can over time improve soil structure, water holding capacity, and can contribute to nutrient retention and supply. They therefore are an important tool in the maintenance of soil quality and in efforts to mitigate soil degradation. Participants discussed the high transactions costs and barriers to entry for organic fertilizer products. None of the countries participating in the policy dialogue offered subsidies for organic fertilizers, although there appears to be growing demand for these products. Production of organic fertilizers from municipal wastes, particularly from South Asia's population dense cities, may also serve an added advantage as a means of ecological waste management and recycling. Studies into the viability of these programs and policy and market support mechanisms could be beneficial, as interest in this subject appears to be growing.

'Open Government Data Platform India. 2019. "Details of Number of Dealers in Each District of India." Accessed October 7, 2019. https://data.gov.in/catalog/details-number-dealers-each-district-india?filters\%5Bfield_catalog_reference\%5D=87050\&format=json\&offset=0\&limit=6 \&sort $\% 5$ Bcreated $\% 5 \mathrm{D}=$ desc 


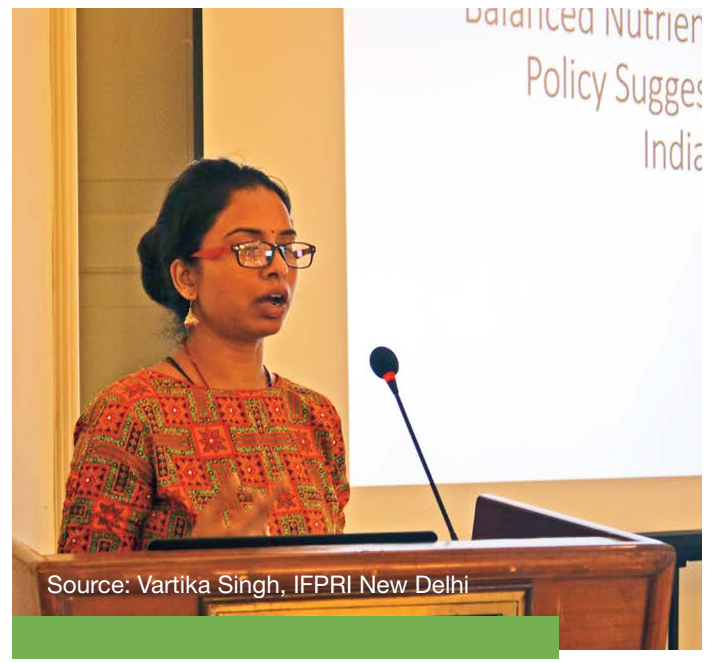

Ms. Mamta, Young Associate, Niti Aayog.

\section{Conclusions}

Seven lessons for policy makers and representatives of the agricultural development sector were identified in this intensive and participatory workshop on balanced nutrient management innovations in South Asia. Key among these are the need to balance micro- with macro-nutrient subsidies, and to organize subsidy programs in ways that assure that secondary macro nutrients - particularly potassium and phosphorous products - are applied alongside fertilizers delivering nitrogen. In addition, additional research and evidence are needed to identify ways to assure that farmers' behaviour changes in response to subsidy programs. Efforts to understand how to link high-level price support policies with field-level actions and activities - for example through research on behavioural nudging could be advantageous in all countries. This lesson has relevance also for the design of extension programs such as India's Soil Health Card program, which could likely be improved through intervention to simplify messages in ways that farmers can both understand and act on.

In addition, participants discussed the need for blended fertilizer products and programs that can support them. Experience with blended products are however uneven in the region markets for blends are nascent in Bangladesh and Nepal in particular. Cross-country technical support on how to develop blending factories and markets could be leveraged to accelerate blended fertilizer markets and to identify ways to assure equitable access to these potentially beneficial products for smallholder farmers.

Similarly, there is a growing interest in organic fertilizers and compost markets, though awareness and evidence for the viability of these products and markets could benefit from thorough research and appropriate policy support. This is particularly important as these products could assist in reducing or reversing the pace of soil quality decline in the region. Lastly, several countries are experimenting with direct cash transfer to farmers over policy level interventions to control macronutrient fertilizer prices. While desirable from a strict economic perspective, this approach also entails risks as it can result in significant price distortion and use of fertilizers on non-target crops. Though theoretically appealing, direct cash transfer schemes are not universally successful and should be implemented only after sufficient research and evidence has been generated to develop carefully implemented systems.

\footnotetext{
2See, for example, Maharashtra state: Hindu Business Line. 2018. "Maharashtra Mission for Organic Farming." August 21. https://www.thehindubusinessline.com/news/maharashtra-mission-for-organic-farming/article24746974.ece.

${ }^{3} \mathrm{Nepal}$ and India have already begun taking steps in this direction. See Press Trust of India. 2019. "Farmers from Nepal Get Organic Farming Training in India." February 22. https://www.business-standard.com/article/pti-stories/farmers-from-nepal-get-organic-farming-training-in-india119022201030_1.html
} 


\section{Acknowledgements}

This policy dialogue was conducted with funding support from the US Agency for International Development (USAID). The views and information presented in this document do not necessarily reflect the views or opinions of USAID or the United States Government, and may not be used for advertising purposes. In addition to all the presenters and participants of the dialogue, we would like to extend special thanks to Shri Yubak Dhoj (Secretary, MoALD Nepal) for Chairing the discussions and offering his remarks and Dr. Arabinda Padhee (Country Head India - ICRISAT) for sharing his experiences from India under this tenure in the Ministry of Fertilizers, Government of India. The authors would like to thank Dr. Dyutiman Choudhury from IFDC Nepal, Dr. Sriniwas Gautam, Ms. Bandana Pradhan and Ms. Smriti Maharjan from CIMMYT Nepal, Dr. Dinabandhu Pandit from CIMMYT Dhaka, Ms. Vartika Singh, Ms. Smriti Saini and Mr. Fahim Mohammad from IFPRI New Delhi, for providing inputs and support in the organization of this dialogue.

\section{Author Details}

Avinash Kishore is a Research Fellow with IFPRI in the South Asia Regional Office of International Food Policy Research Institute (IFPRI), New Delhi, while Muzna Alvi is an Associate Research Fellow in the Environment and Production Technology Division, also with IFPRI and based in New Delhi. Timothy J. Krupnik is the Project Leader for the Cereal Systems Initiative for South Asia and Senior Scientist and Systems Agronomist with the International Maize and Wheat Improvement Center (CIMMYT), Dhaka, Bangladesh.

\section{More about CSISA}

CSISA works to encourage pathways towards the widespread adoption of resource-conserving practices, technologies and services that increase yields with lower water, labor and input costs.
CSISA supports mainstreaming innovations in national-, stateand district-level government programs to improve long-term impacts achieved through investments in the agricultural sector.
CSISA and its partners generate and disseminate new knowledge on cropping system management practices that can withstand the impacts of climate change in South Asia.

\footnotetext{
Though strategic research and engagement, CSISA works to improve the policy environment to facilitate the adoption of sustainable intensification technologies.
}

\section{Build strategic partnerships} that can sustain and enhance the scale of benefits accrued through improving cereal system productivity. 
The Cereal Systems Initiative for South Asia (CSISA) is a regional initiative to sustainably increase the productivity of cereal-based cropping systems, thus improving food security and farmers' livelihoods in Bangladesh, India and Nepal. CSISA works with public and private partners to support the widespread adoption of resource-conserving and climate-resilient farming technologies and practices. The initiative is led by the International Maize and Wheat Improvement Center (CIMMYT), implemented jointly with the International Food Policy Research Institute (IFPRI) and the International Rice Research Institute (IRRI), and is funded by the US Agency for International Development (USAID) and the Bill \& Melinda Gates Foundation. 